\title{
Perancangan Boks Truk Pengangkut Buah-Buahan
}

\author{
Johan K. Santoso ${ }^{1}$, Fandi D. Suprianto ${ }^{2 *}$ \\ 1,2 Program Studi Teknik Mesin, Universitas Kristen Petra \\ Jl. Siwalankerto 121-131, Surabaya 60236. Indonesia \\ * Penulis korespondensi; E-mail: fandi@petra.ac.id
}

\begin{abstract}
ABSTRAK
Adanya permintaan buah stroberi segar yang terus meningkat untuk kebutuhan dalam negeri maupun luar negeri mendorong penggunaan boks pendingin pada proses transportasi. Selain pendinginan, juga diperlukan humidifikasi ruangan agar buah stroberi dapat sampai dengan kondisi masih segar. Dalam perancangan ini, boks pendingin di desain agar mampu mempertahankan suhu $10^{\circ} \mathrm{C}$ dan $90 \% \mathrm{RH}$. Untuk dapat mencapai suhu tersebut dilakukan perhitungan untuk mengetahui beban pendinginan dan diperlukan simulasi untuk melihat pengaturan penyusunan boks buah agar udara dapat tersebar secara merata. Setelah proses simulasi dan perhitungan teleh diselesaikan, didapatkan bahwa sistem pendingin boks truk yang dikeluarkan oleh produsen Denso mampu mencapai kondisi steady dalam waktu 10 menit dan dapat mencukupi kebutuhan untuk pendinginan ruangan meskipun sudah terbeban oleh komoditas dan humidifikasi ruangan. Sedangkan untuk susunan boks buah yang dipakai adalah disusun ke atas sebanyak 5 boks, 3 ke belakang, dan 3 ke samping untuk 1 buah pallet.
\end{abstract}

Kata kunci: Refrigeransi; humidifikasi; heat exchanger.

\section{ABSTRACT}

The demand for fresh strawberries which continues to increase for domestic and foreign needs encourages the use of cooling boxes in the transportation process. In addition to cooling, humidification of the room is also needed so that strawberries can arrive at a fresh condition. In this design, the cooling box is designed to be able to maintain a temperature of $10^{\circ} \mathrm{C}$ and $90 \% \mathrm{RH}$. To be able to reach the temperature, a calculation is carried out to determine the cooling load and a simulation is needed to see the arrangement of fruit boxes so that air can be spread evenly. After the simulation process and calculations have been completed, it was found that the truck crib cooling system issued by the Denso manufacturer was able to reach a steady state within 10 minutes and could meet the need for cooling the room even though it was loaded by commodities and room humidification. As for the arrangement of fruit boxes used are arranged upwards of 5 boxes, 3 backwards. and 3 sideways for 1 fruit palette.

Keywords: Refrigeration; humidification; heat exchanger.

\section{PENDAHULUAN}

Stroberi (Fragaria chiloensis L.) merupakan salah satu komoditi holtikultura yang berpotensi besar untuk dikembangkan secara komersial. Hal itu dilihat dari daya serap pasar dan permintaan dunia dari tahun ke tahun yang meningkat. Data ekspor buah segar terutama stroberi dapat dilihat pada Tabel 1 permintaan akan stroberi baik dari dalam maupun luar negeri yang tinggi menuntut stroberi harus diterima dalam keadaan yang baik. Pengiriman stoberi dari petani ke konsumen membutuhkan waktu panjang untuk transportasi, sehingga pada saat mentransportasikan, mutu harus dijaga melalui pengkondisian lingkungan penyimpanannya. Pengkondisian lingkungan penyimpanan dilakukan untuk menghindari kerusakan. Kerusakan-kerusakan tersebut berupa resiko lingkungan (environmental hazards), misalnya akibat suhu dan kelembaban, resiko fisik (gesekan, impak, tekanan, dan benturan) serta resiko lainnya seperti investasi organisme, kontaminasi dan pencurian. Seiring dengan semakin meningkatnya permintaan jumlah produksi buah stroberi dengan kondisi mutu yang lebih baik oleh konsumen, maka diperlukan suatu penanganan pascapanen yang tepat untuk dapat mengurangi kerusakan tersebut misalnya kerusakan akibat suhu dan kelembaban.

Oleh karena itu dibutuhkan alat transportasi dengan cold storage yang memadai untuk menjaga suhu dan kelembaban dari buah stroberi. Dalam pembuatan cold storage pada alat transportasi perlu memperhatikan konstruksi dan dimensi kemasan, jumlah dan dimensi komoditas yang dikemas, dan sifat fisiologis pascapanen produk hortikultura harus diperhatikan agar dapat memberikan perlindungan yang optimal.

Tujuan dari penelitian adalah melakukan desain cold storage pada mobil boks agar dapat 
menyimpan buah stroberi dalam kondisi $10^{\circ} \mathrm{Cdan} 85$ $90 \% \mathrm{RH}$ pada saat ditransportasikan. Sedangkan untuk manfaat perancangan adalah menurunkan resiko buah stroberi yang rusak sewaktu proses transportasi karena temperatur dan kelembaban yang tidak sesuai.

Tabel 1. Ekspor buah segar Indonesia ke negara-negara Eropa

\begin{tabular}{llrrrrr}
\hline \multirow{2}{*}{ No Komoditas } & \multicolumn{5}{c}{ Jumlah Ekspor (ton) } \\
\cline { 2 - 7 } & Ktroberi & 2475 & 2267 & 6 & 2 & 1187.5 \\
\hline 1 & Nanas & 746 & 871 & 97 & 0 & 428.5 \\
2 & Nana & 987 & 2 & 0 & 33 & 255.5 \\
3 & Mangga & 891 & 42 & 24 & 56 & 253.5 \\
4 & Manggis & 235 & 348 & 13 & 0 & 149 \\
5 & Rambutan & 386 & 9 & 60 & 132 & 146.8 \\
6 & Pisang & 479 & 5 & 36 & 0 & 130 \\
7 & Buah tropis & & & & & \\
& lainnya & & & & & \\
8 & Buah lainnya & 826 & 1590 & 0.9 & 12 & 634.2 \\
\hline
\end{tabular}

\section{METODOLOGI PENELITIAN}

Penelitian ini dilakukan dengan beberapa tahapan secara sistematis yang telah dirancang. Tahapan dalam penelitian dapat dilihat pada Gambar 1.

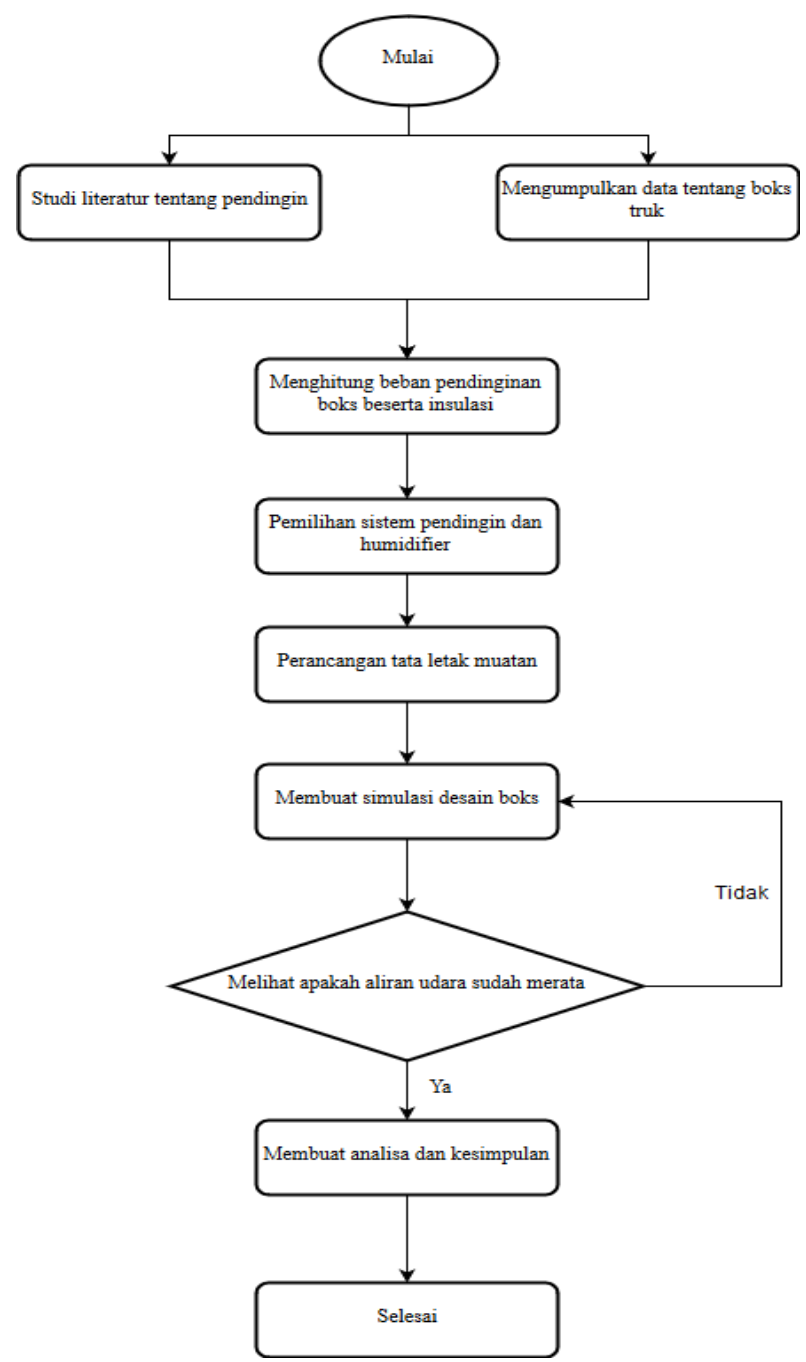

Gambar 1. Diagram Metode Penyelesaian Tugas Akhir

\section{Prosedur Pengujian}

Metode penelitian diawali dengan studi literatur tentang pendingin bersamaan dengan mengumpulkan data tentang boks truk sehingga dapat diketahui berapa volume dari ruangan yang dimiliki. Setelah itu dilakukan perhitungan tentang beban pendinginan boks beserta insulasinya agar dapat mempertahankan suhu ruangan konstan pada $10^{\circ} \mathrm{C}$ dan kelembaban berkisar antara 85- 90\%Rh. Kemudian ketika beban pendinginan sudah diketahui dilanjutkan dengan pemilihan sistem pendinginan dan humidifier. Setelah itu dilakukan perancangan tata letak muatan pada boks truk dilanjutkan dengan membuat simulasi sesuai dengan rancangan. Pada simulasi dilakukan pengamatan apakah aliran udara pada boks truk sudah merata yang diindikasikan oleh sebaran temperatur di setiap pallet tidak lebih dari $10^{\circ} \mathrm{C}$. Apabila ada pallet yang suhunya lebih dari $10^{\circ} \mathrm{C}$, maka dilakukan desain ulang dari boks truk.

Beban-beban yang perlu dihitung beban radiasi secara langsung, beban radiasi secara difusi, beban radiasi secara refleksi, beban dari udara sekitar, beban dari panas knalpot, beban dari panas mesin, beban dari respirasi produk, beban dari proses humidifikasi dan beban dari panas motor kipas.

Beban radiasi secara langsung:

$Q_{D I R}=\sum_{\text {surface }} S \tau l_{D I R} \cos$

Beban radiasi secara difusi:

$Q_{D I F}=\sum_{\text {surface }}^{\infty} S \tau l_{D I F}$

Beban radiasi secara refleksi:

$Q_{R E F}=\sum_{\text {surface }}^{\infty} S \tau \imath_{R E F}$

Beban dari udara sekitar:

$Q_{A M B}=\sum_{\text {surface }} S U\left(T_{s}-T_{i}\right)$

Beban dari panas knalpot:

$\dot{Q}_{E X H}=S_{E X H} U\left(T_{E X H}-T_{i}\right.$

Beban dari panas mesin

$\dot{Q}_{E N G}=S_{E N G} U\left(T_{E N G}-T_{i}\right.$

$Q=\left(\frac{m \times W}{3600}\right)$

Beban dari proses humidifikasi:

$Q=v \times \rho \times(\Delta h)$

Beban dari panas motor kipas:

$Q=$ fans $x$ wattage $x(1-$ efficiency $)$ 
Insulasi boks yang digunakan:
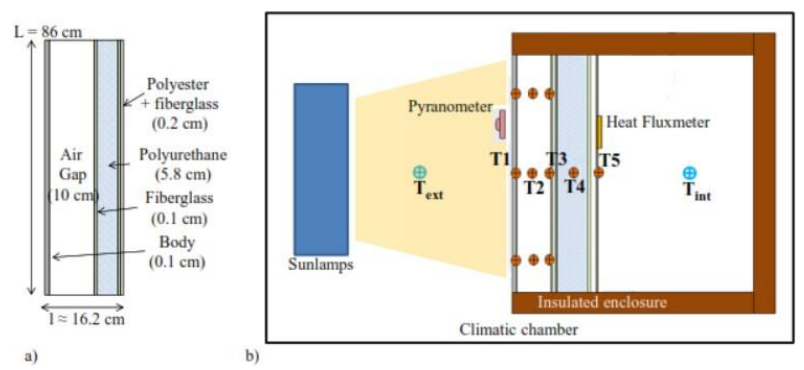

Gambar 2. Susunan Insulasi Boks

\section{HASIL DAN PEMBAHASAN}

Tabel 2. Beban kalor tiap bulan

\begin{tabular}{cc}
\hline Bulan & Total Perhitungan Beban (watt) \\
\hline Januari & 2642,34 \\
Februari & 1843,93 \\
Maret & 2358,27 \\
April & 2982,61 \\
Mei & 2694,19 \\
Juni & 3293,82 \\
Juli & 2706,72 \\
Agustus & 3060,70 \\
September & 2337,86 \\
Oktober & 1811,42 \\
November & 2647,92 \\
Desember & 2699,67 \\
\hline
\end{tabular}

\section{Pemilihan Pendingin dan Humidifier}

Tipe pendingin chiller yang akan digunakan adalah SS32MN-S2MN1.

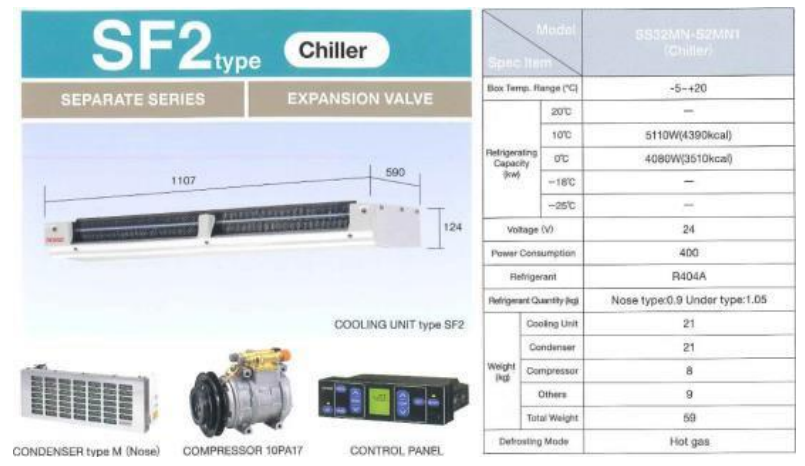

Gambar 3. Spesifikasi Chiller SS32MN-S2MN1

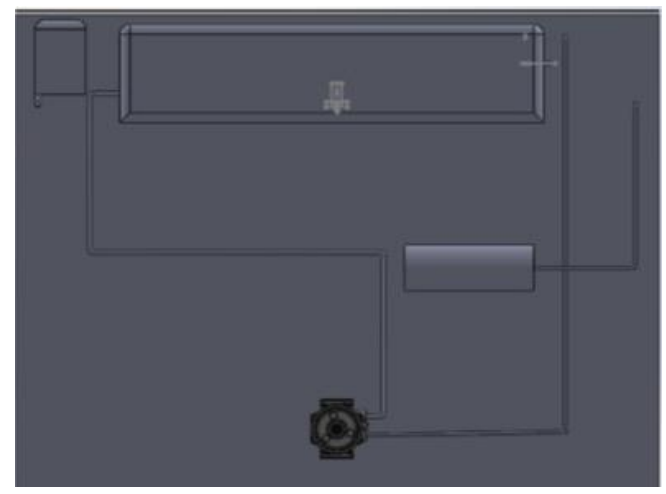

Gambar 4. Tampak Depan Boks
Kompresor yang digunakan adalah tipe 10PA17 yang digerakan oleh tenaga dari mesin truk. Untuk kondensor yang digunakan bertipe nose yang akan diletakkan pada bagian depan boks. Sedangkan fan yang berada pada evaporator berjumlah 2 buah dan dapat memindahkan volume udara sebesar 1500 $\mathrm{m}^{3} / \mathrm{jam}$. Sedangkan untuk mencukupi kebutuhan humidifikasi ruangan, digunakan produk oleh Exair dengan tipe SR2010SS yang memiliki spesifikasi yaitu $3,0 \frac{L}{\text { jam }}$ pada tekanan 4,1 bar dan ukuran pipa 0,625". Pemilihan nozzle tersebut karena memiliki kapasitas yang sudah mencukupi untuk kebutuhan humidifikasi ruangan, tidak memerlukan air yang bertekenan tinggi, dan memiliki katup yang akan menutup bila tekanan udara tidak memenuhi sehingga ruangan tidak menjadi terlalu jenuh akibat tetesan air dari sisa nozzle.

Tangki air untuk kebutuhan humidifier berkapasitas 5 liter sehingga dapat mencukupi kebutuhan air hingga 3 jam perjalanan. Tangki air akan diletakan bersebelahan dengan kondensor. Kompresor udara yang digunakan untuk proses humidifikasi ruangan berkapasitas maksimum 150 psi, tangki udara sebesar 3 liter, memiliki tegangan $12 \mathrm{~V}$, arus sebesar 15A. Mempunyai sensor otomatis yang akan mematikan pompa bila mendeteksi suhu kompresor berada di atas $80^{\circ} \mathrm{C}$, mengisi tangki pada tekanan 100 psi dan mati pada 125 psi. Kompresor udara akan diletakan pada bagian depan boks. Untuk pengatur kelembaban menggunakan modul hygrostat yang bersifat analog yang berfungsi sebagai relay terhadap listrik kompresor udara.

\section{Simulasi Aliran Udara Boks Pendingin}

Prosedur flow simulation solidwork:

1. Membuat parts-parts yang diperlukan untuk simulasi

2. Melakukan assembly-assembly parts sesuai dengan tempat yang telah dirancang.

3. Membuka add-ins flow simulation pada solidwork

4. Memilih menu wizard pada kolom flow simulation agar dapat menentukan apakah aliran udara pada bagian dalam atau luar, fluida yang akan disimulasikan, hingga bahan dinding yang akan disimulasikan terbuat dari apa.

5. Menentukan boundary conditions dari simulasi.

6. Menetapkan initial conditions sebelum simulasi dijalankan.

7. Menentukan masukkan dan keluaran udara dari evaporator.

8. Menjalankan simulasi.

Setelah simulasi dijalankan, berikutnya ditentukan kondisi-kondisi hasil yang perlu dilihat dengan cara:

1. Membuat section view.

2. Membuat cut plot agar dapat melihat parameterparameter yang diperlukan, pada menu cut plot 
perlu dilakukan pemilihan salah satu kondisi yang dibutuhkan seperti temperatur dalam ruangan.

3. Dengan cara yang sama, cut plot berikutnya untuk kecepetan aliran udara dapat dibuat.

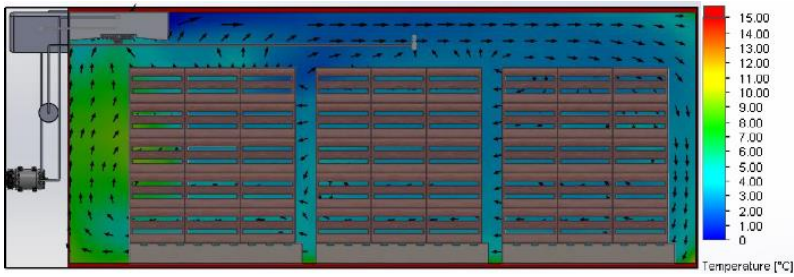

Gambar 5. Suhu pada boks pendingin

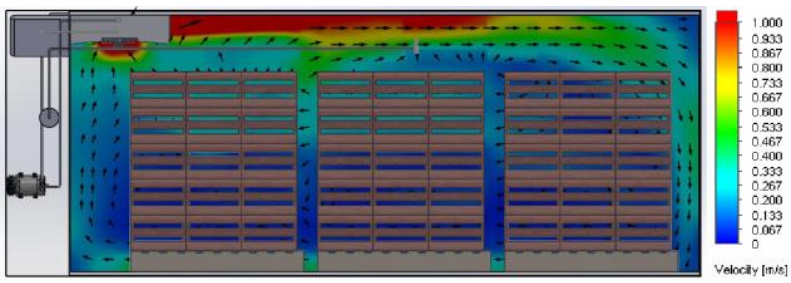

Gambar 6. Kecepatan aliran udara pada boks pendingin

Hasil simulasi pada gambar 5. dan gambar 6 . menunjukkan bahwa persebaran udara sudah merata dan berada pada suhu di bawah $10^{\circ} \mathrm{Cyang}$ berarti sudah sesuai untuk penyimpanan buah stroberi.
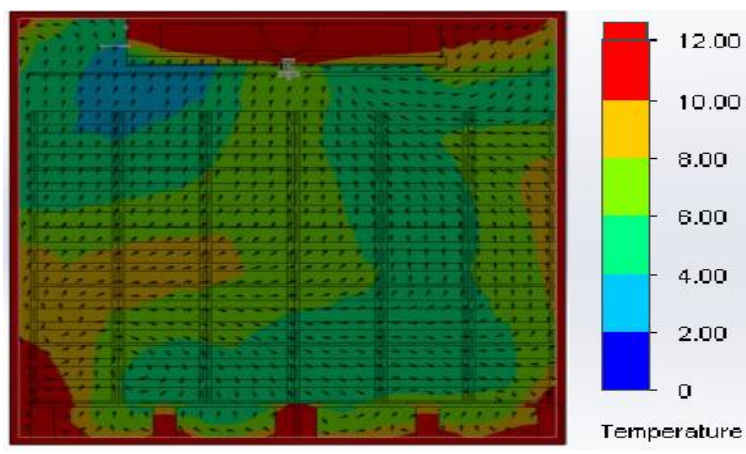

Temperature $\left[{ }^{\circ} \mathrm{C}\right]$

Gambar 7. Suhu pada Boks Pendingin tanpa Difusser dan Suhu $0^{\circ} \mathrm{C}$ beserta Alat Humidifikasi Ruangan terhadap Bidang XY pada Baris Pallet Boks Pertama
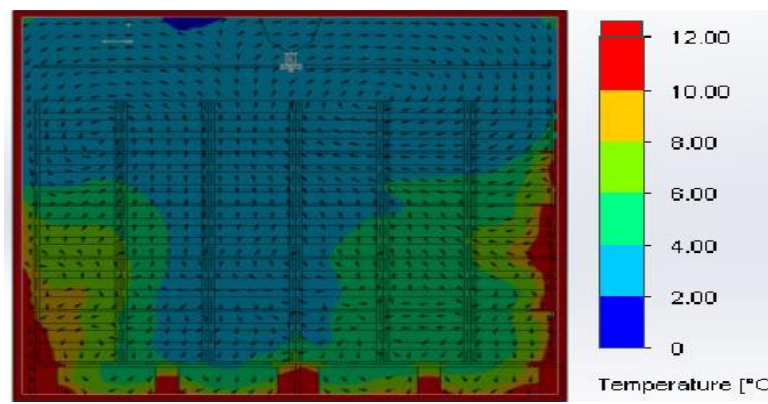

Gambar 8. Suhu pada Boks Pendingin tanpa Difusser dan Suhu $0^{\circ} \mathrm{C}$ beserta Alat Humidifikasi Ruangan terhadap Bidang XY pada Baris Pallet Boks Kedua

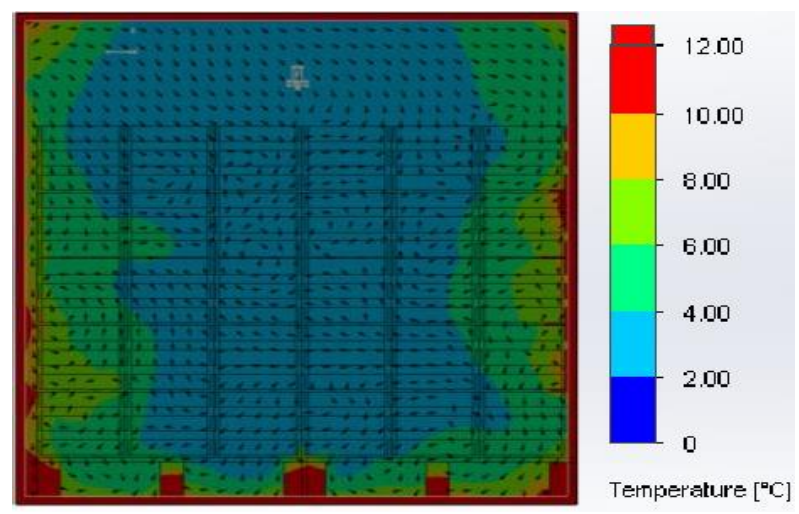

Gambar 9. Suhu pada Boks Pendingin tanpa Difusser dan Suhu $0^{\circ} \mathrm{C}$ beserta Alat Humidifikasi Ruangan terhadap Bidang XY pada Baris Pallet Boks Ketiga

Pada simulasi yang ketujuh, dapat dilihat bahwa penyebaran udara sudah merata dan berada pada suhu maksimal $10^{\circ} \mathrm{C}$ hingga ke baris pallet boks pertama. Karena peninggian pallet tersebut, tidak hanya mengakibatkan buah lebih dingin karena posisi yang lebih tinggi tetapi juga menyebabkan udara dapat melewati bagian bawah pallet.

\section{KESIMPULAN}

Dari hasil penelitian ini didapatkan bahwa temperatur dalam ruangan boks truk dapat tercapai sampai dengan temperatur target. Namun untuk mencapai temperatur boks $10^{\circ} \mathrm{C}$ adalah dengan memodifikasi tinggi pallet boks truk sehingga tidak sesuai dengan yang ada di pasaran. Sistem pendingin menyerap banyak kelembaban dari udara sehingga memang diperlukan humidifikasi ruangan untuk mengangkut buah stroberi agar tetap dalam kondisi segar

\section{DAFTAR PUSTAKA}

[1] Firdaus, N. , 2010, . Kajian Teknik Penyimpanan dan Pengemasan Buah Stroberi (Fragaria Chiloensis L.) selama Transportasi. Bogor: Insitut Pertanian Bogor

[2] Fayazbakhsh, M. A., \& Bahrami, M. , 2013, Comprehensive Modeling of Vehicle Air Conditioning Loads Using Heat Balance Method. SAE International, 1-14.

[3] Becker, Ph.D., P.E., B. R., \& Fricke, B. A. ,n.d, Transpiration and Respiration of Fruits and Vegetables. Kansas: University of Missouri.

[4] Glouannec, P., Michel, B., Delamarre, G., \& Grohens, Y., 2014, Experimental and Numerical Study of Heat Transfer Across Insulation Wall of a Refrigerated Integral Panel Van, HAL Archives Ouvertes, 196-204. 